\title{
Dynamic stress relaxation of orthodontic thermoplastic materials in a simulated oral environment
}

\author{
Dongyu FANG ${ }^{1}$, Ning ZHANG ${ }^{1}$, Hui CHEN²${ }^{2}$ and Yuxing BAI ${ }^{1}$ \\ ${ }^{1}$ Department of Orthodontics, School of Stomatology, Capital Medical University, Tian Tan Xi Li, \#4, Dongcheng District, Beijing 100050, China \\ ${ }^{2}$ School of Biomedical Engineering, Capital Medical University, You An Men Wai Xi Tou Tiao, \#10, Fengtai District, Beijing 100069, China \\ Corresponding author, Yuxing BAI; E-mail: byuxing@263.net
}

\begin{abstract}
Mechanical properties are crucial for screening orthodontic thermoplastic materials for invisible aligners. However, most of previous studies were carried out within laboratory conditions which limit our understanding of the mechanical behaviors of aligners within oral environment. In this study, we studied the dynamic stress relaxation of thermoplastic materials by combination of Bose ElectroForce and a homemade temperature-controlled water bath. The 3-h stress relaxation curves of five orthodontic thermoplastic materials were measured within $37^{\circ} \mathrm{C}$ water bath as well as comparatively in ambient atmospheric environment $\left(\sim 20^{\circ} \mathrm{C}\right)$. The percentage residual stress at $0,30,60,90,120,150$, and 180 min was selected for statistical analyses. As expected, the experimental results showed that the residual stress within all five materials decreased with time, and that this process was significantly accelerated in the $37^{\circ} \mathrm{C}$ water bath $(p<0.05)$. Compared with other materials, Erkodur and Masel exhibited slower relaxing rates in the $37^{\circ} \mathrm{C}$ water bath $(p<0.05)$.
\end{abstract}

Keywords: Orthodontic thermoplastic materials, Stress relaxation, Invisible aligners, Home-made devices, Simulated oral environment

\section{INTRODUCTION}

Thermoplastic materials have been widely used in dental medicine as orthodontic retainers, temporomandibular joint splints, periodontal splints, mouth guards, and bleaching trays due to their outstanding formability, superior shape-memory properties, and excellent esthetic characteristics ${ }^{1-4)}$. Thanks to the development of computer-aided design/computer-aided manufacturing techniques in the past two decades, transparent thermoplastic materials have been precisely designed and fabricated into a series of clear, removable tooth aligners for orthodontics ${ }^{5,6}$. This orthodontic treatment modality, the most renowned of which is Invisalign, becomes more and more attractive than traditional fixed appliances because it offers a number of advantages including less pain, fewer office visits, virtually transparent, and can be removed for eating and brushing ${ }^{7}$. Despite being increasingly accepted by patients, the mechanical properties and tooth-moving process of orthodontic thermoplastic appliances remains unclear 8,9 .

Clinically, an archwire, when inserted and deformed, will deliver a corresponding force (i.e., orthodontic force) and move a target tooth towards its memorized position. Over time, the tooth moves, the archwire recovers its shape, and the force decreases until it falls below the 'threshold'10). Within its elastic limit, an archwire generally delivers orthodontic force proportional to its deformation (with the exception of certain nickel-titanium wires). Therefore, tooth movement can be predicted and controlled relatively well. In contrast, the stress within thermoplastic materials induced by initial deformation tends to cause the deterioration of mechanical properties with time because they are viscoelastic ${ }^{11}$. Such a phenomenon, called stress relaxation, results in additional loss of the ability of a thermoplastic appliance to move a tooth over time, which makes predicting orthodontic forces and tooth movement much more challenging. The time course of stress relaxation of thermoplastic materials within the oral environment is crucial, not only for screening materials intended for dental applications, but also for better understanding the mechanism and process of Invisalign orthodontics.

In the past two decades, several studies have been performed on the mechanical properties of various dental thermoplastic products ${ }^{12-15)}$. These previous studies have shown that the mechanical properties including elastic modulus, tensile yield stress, and stress relaxation depend on the type of thermoplastic material, the measuring technique (e.g., the amount of strain), and testing environment (e.g., temperature and moisture). However, most of previous studies were carried out on the thermoformed samples pretreated by immersing in distilled water at $37^{\circ} \mathrm{C}$ to simulate intraoral environment. This limits our understanding of the mechanical behaviors of orthodontic thermoplastics within mouth, where both temperature and moisture play a role for a relatively long period. Here, we designed a temperature-controlled water bath that was used to study the dynamic stress relaxation of thermoplastic materials in a simulated oral environment. The 3-h stress relaxation of five commercial orthodontic thermoplastic materials was measured in a water bath at $37^{\circ} \mathrm{C}$, as well as in an ambient atmospheric environment. The stress-strain behavior of different materials within different testing environments was compared and further discussed. 


\section{MATERIALS AND METHODS}

\section{Materials}

Five commercial orthodontic thermoplastic materials were used in the present study (Table 1). For stress relaxation testing, all the samples were fabricated into dumbbell-shaped specimens according to the ISO standard 527-3 type $5^{16)}$. Briefly, the specimen is $115 \mathrm{~mm}$ long, $1.0 \mathrm{~mm}$ thick, $25.0 \mathrm{~mm}$ wide at both ends, and 6.0 $\mathrm{mm}$ wide in the narrow middle part. The narrow middle part of the specimen is $\sim 33.0 \mathrm{~mm}$ long. In general, such a configuration will induce deformation or breakage occurring in the middle area ( $25.0 \mathrm{~mm}$ long) of the specimen when it is stretched from the two ends ${ }^{17)}$.

Set-up of the temperature-controlled water bath system To simulate oral environment, we set up a temperaturecontrolled water bath system that was adapted to the Bose ElectroForce test instrument (ELF 3100, Bose Corp., Framingham, MA, USA). The ELF 3100 is the smallest instrument in the ElectroForce product family and well-suited for micro-characterization of biomaterials and tissues. As shown in Fig. 1, this experimental set-up is composed of three interconnected parts: (1) a glass chamber, $50.0 \mathrm{~mm}$ in diameter and $75.0 \mathrm{~mm}$ in height, designed to accommodate testing specimens, with one water jacket inlet and outlet located in the upper right and lower left walls, respectively; (2) a water bath that serves as a reservoir, offering temperature-controlled distilled water for the glass chamber and recycling the effluent water from it as well; and (3) a flow control pump that is used to connect the water bath with the glass chamber and regulate fluid flow velocity.

Before experiments, two parallel rectangular openings ( $\sim 27.0 \mathrm{~mm}$ long and $\sim 2.0 \mathrm{~mm}$ wide) were cut on the top and bottom of the glass chamber; subsequently, the bottom one was sealed with silicon sealant, dried for $48 \mathrm{~h}$, then cut by a sharp knife across the axis of the sealant. The sealant slit is elastic, thereby producing a squeezing force after the dumbbellshaped specimen is passed through. To further avoid water leakage during experiments, the possible fissure between the specimen and slit was wrapped with Parafilm M. A small hole was drilled on the top of the glass chamber across which a thermometer was installed for real-time monitoring of the temperature of the fluid inside the glass chamber.

Once the specimen was loaded, the water bath, flow control pump, and specimen-loaded glass chamber were interconnected, as shown in Fig. 1. An iron support stand and an extension clamp were used to fix the glass chamber, and the specimen was held vertically by the upper (loading) and lower (fixing) clamps of the ELF 3100 equipment. The experiment began once the glass chamber was filled with temperature-controlled water from the water bath. The temperature of the

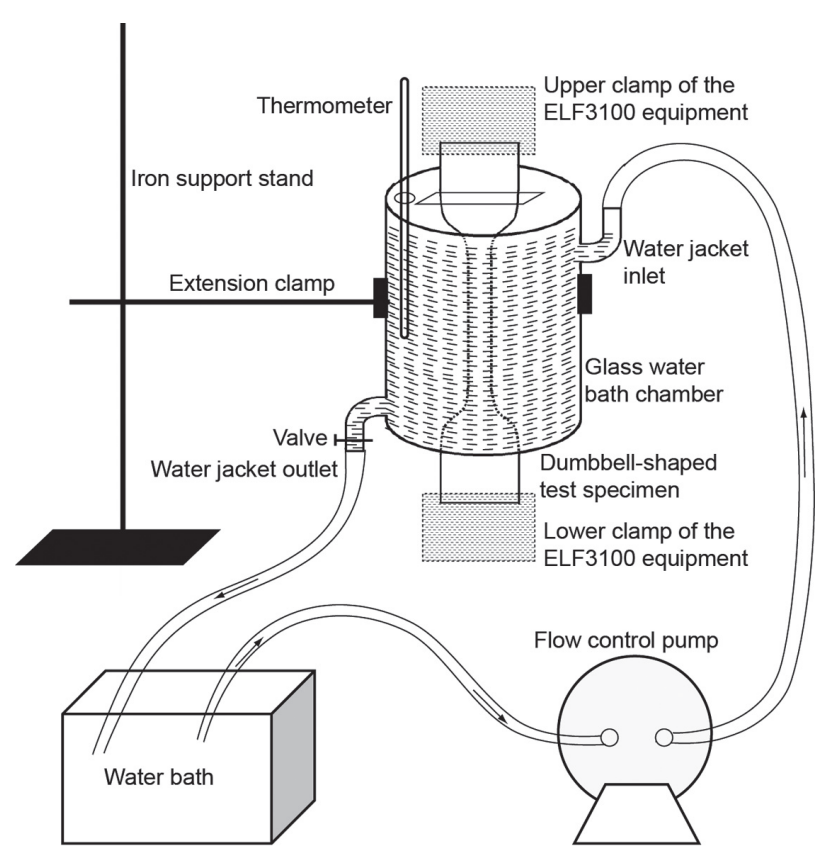

Fig. 1 Schematic diagram of the temperature-controlled water bath and mechanical testing of the orthodontic thermoplastic materials in a simulated oral environment.

Table 1 Characteristics and description of the materials used in this study

\begin{tabular}{|c|c|c|c|c|}
\hline Product name & Thickness & Manufacturer & Item number & Component (MSDS) a \\
\hline Erkodur & $1.0 \mathrm{~mm}$ & $\begin{array}{c}\text { Erkodent Erich Kopp, } \\
\text { Pfalzgrafenweiler, Germany }\end{array}$ & 521210 & $\begin{array}{c}\text { Polyethyleneterephthalat-Glycol } \\
\text { Copolyester (PETG) }\end{array}$ \\
\hline Biolon & $1.0 \mathrm{~mm}$ & Dreve Dentamid, Unna, Germany & D-42396 & Polyethylene terephtalate \\
\hline Masel $^{\mathrm{b}}$ & $1.0 \mathrm{~mm}$ & Ortho Organizers Inc., Carlsbad, CA, USA & $2032-081$ & Copolyester \\
\hline Keystone $^{b}$ & $1.0 \mathrm{~mm}$ & Keystone Industries, Myerstown, PA, USA & 9615060 & Copolyester \\
\hline Duran & $1.0 \mathrm{~mm}$ & Scheu-dental, Iserlohn, Germany & 3415 & PETG \\
\hline
\end{tabular}

a Component as obtained from the manufacturers' Material Safety Data Sheet.

$\mathrm{b}$ The name of manufacturer is used as no specific product name is found. 
water within the glass chamber was controlled by regulating the temperature of the water reservoir and the fluid velocity through the pump. The idea is to keep the water within the glass chamber nearly full and regulate the fluid recycling so it is as slow as possible (for less disturbance and for economic reasons), which allows the specimen to be measured within water bath at target temperature.

\section{Stress relaxation testing and statistics}

Stress relaxation testing was carried out at $37^{\circ} \mathrm{C}$ within the water bath, and in an ambient atmospheric environment $\left(\sim 20^{\circ} \mathrm{C}\right)$, with the ELF 3100 equipment. Each test consisted of three parts; $15 \mathrm{~s}$ for stretching the specimen up to $1.25 \mathrm{~mm}$ (i.e., $5 \mathrm{~mm} / \mathrm{min}$ of tensilevelocity and a total $\sim 5 \%$ of strain), $5 \mathrm{~s}$ for system stabilization, and $3 \mathrm{~h}$ for stress relaxation. Three specimen duplicates were measured for each material in both test environments. Stress values were recorded at $0.02 \mathrm{~s}$ intervals. For each specimen, the percentage residual stress was calculated as $\left(\mathrm{N}_{\mathrm{n}} / \mathrm{N}_{0}\right) \times 100$, where $\mathrm{N}_{\mathrm{n}}$ is the residual stress value at relaxing time $T_{n}$, and $\mathrm{N}_{0}$ is the initial stress value at zero minutes. It should be clarified that the $5 \%$ strain was selected here because it was about $50 \%$ of the yield strain, which was previously determined to be $9-10 \%$ for those batches. To minimize intra-sample variance, stress relaxation curves were drawn based on the percentile of residual stress.

To compare the differences between the two testing conditions and among different materials, the residual stress percentiles at $0,30,60,90,120,150$, and 180 min were selected and analyzed with the statistical software SPSS v17.0 (SPSS Inc., Chicago, IL, USA). Repeated-measures analysis of variance (ANOVA), independent $t$ test, multi-way ANOVA, and Bonferroni's test were used to determine the presence of statistically significant differences.

Additionally, initial stress at 5\% strain of above 30 specimens, with and without glass-chamber-loading, was comparatively measured to confirm whether or not the physical fixing of the specimen in the glass chamber would affect the stress measurement. As shown in Tables 2 and 3, the initial stress values are

Table 2 Comparison of initial and residual stress of the different materials in the atmospheric environment

\begin{tabular}{|c|c|c|c|c|c|c|c|c|}
\hline \multirow{2}{*}{ Materials } & \multirow{2}{*}{$\begin{array}{l}\text { Initial stress } \\
(\mathrm{MPa})\end{array}$} & \multicolumn{7}{|c|}{ Residual stress, \% (SD) } \\
\hline & & $0 \mathrm{~min}$ & $30 \mathrm{~min}$ & $60 \min$ & $90 \mathrm{~min}$ & $120 \mathrm{~min}$ & $150 \mathrm{~min}$ & $180 \mathrm{~min}$ \\
\hline Erkodur & $41.66(1.63)$ & $100.00(0.00)$ & $94.58(1.92)$ & $93.48(2.08)$ & $92.71(2.26)$ & $92.32(2.13)$ & $92.01(1.86)$ & $91.88(1.72)$ \\
\hline Biolon & $35.29(1.68)$ & $100.00(0.00)$ & $93.50(1.56)$ & $92.11(1.89)$ & $91.26(2.00)$ & $90.54(2.00)$ & $89.93(2.19)$ & $89.51(2.21)$ \\
\hline Masel & $41.33(6.51)$ & $100.00(0.00)$ & $93.67(2.43)$ & $92.14(2.65)$ & $91.17(2.91)$ & $90.50(3.02)$ & $89.82(3.20)$ & $89.35(3.52)^{a}$ \\
\hline Keystone & $45.67(0.56)$ & $100.00(0.00)$ & $91.62(1.07)$ & $89.82(1.67)$ & $88.56(1.64)$ & $87.52(1.44)^{\mathrm{a}}$ & $86.76(1.49)^{\mathrm{a}}$ & $86.10(1.66)^{\mathrm{a}}$ \\
\hline Duran & $40.39(1.38)$ & $100.00(0.00)$ & $91.22(1.48)$ & $89.41(1.58)$ & $88.09(1.69)^{\mathrm{a}}$ & $87.29(1.58)^{\mathrm{a}}$ & $86.50(1.82)^{\mathrm{a}}$ & $85.80(1.59)^{\mathrm{a}}$ \\
\hline Average & $40.87(4.36)$ & $100.00(0.00)$ & $92.92(1.43)$ & $91.39(1.72)$ & $90.36(1.96)$ & $89.63(2.16)$ & $89.01(2.33)$ & $88.53(2.56)$ \\
\hline
\end{tabular}

$\mathrm{SD}$, standard deviation.

a Significantly different from Erkodur at the same time point by Bonferroni's test.

Table 3 Comparison of the initial and residual stress of the different materials in the $37^{\circ} \mathrm{C}$ water bath

\begin{tabular}{|c|c|c|c|c|c|c|c|c|}
\hline \multirow{2}{*}{ Materials } & \multirow{2}{*}{$\begin{array}{l}\text { Initial stress } \\
(\mathrm{MPa})\end{array}$} & \multicolumn{7}{|c|}{ Residual stress, \% (SD) } \\
\hline & & $0 \min$ & $30 \mathrm{~min}$ & $60 \mathrm{~min}$ & $90 \mathrm{~min}$ & $120 \mathrm{~min}$ & $150 \mathrm{~min}$ & $180 \mathrm{~min}$ \\
\hline Erkodur & $37.26(2.55)$ & $100.00(0.00)$ & $85.82(2.17)$ & $78.93(2.29)$ & $74.49(2.26)$ & $71.73(2.19)$ & $69.10(2.09)$ & $66.49(2.21)$ \\
\hline Biolon & $37.70(2.64)$ & $100.00(0.00)$ & $73.16(2.15)^{\mathrm{a}, \mathrm{b}}$ & $62.02(3.22)^{\mathrm{a}, \mathrm{b}}$ & $58.65(3.45)^{a, b}$ & $57.36(4.09)^{a, b}$ & $54.69(2.92)^{\mathrm{a}, \mathrm{b}}$ & $53.24(3.19)^{\mathrm{a}, \mathrm{b}}$ \\
\hline Masel & $41.46(1.87)$ & $100.00(0.00)$ & $83.25(1.77)$ & $77.45(2.17)$ & $73.26(2.40)$ & $69.39(2.63)$ & $67.51(2.66)$ & $65.27(2.51)$ \\
\hline Keystone & $42.24(4.30)$ & $100.00(0.00)$ & $72.94(3.64)^{\mathrm{a}, \mathrm{b}}$ & $64.15(4.03)^{\mathrm{a}, \mathrm{b}}$ & $58.99(3.59)^{a, b}$ & $56.05(3.93)^{a, b}$ & $52.64(3.97)^{\mathrm{a}, \mathrm{b}}$ & $50.22(4.14)^{\mathrm{a}, \mathrm{b}}$ \\
\hline Duran & $37.32(2.47)$ & $100.00(0.00)$ & $77.12(4.38)^{a, b}$ & $69.96(5.28)^{\mathrm{a}, \mathrm{b}}$ & $65.56(5.32)^{a, b}$ & $60.73(5.01)^{a, b}$ & $57.12(4.20)^{\mathrm{a}, \mathrm{b}}$ & $55.48(5.00)^{\mathrm{a}, \mathrm{b}}$ \\
\hline average & $39.20(3.33)$ & $100.00(0.00)$ & $76.62(4.82)$ & $68.40(6.91)$ & $64.12(6.88)$ & $60.88(6.00)$ & $57.99(6.61)$ & $56.05(6.51)$ \\
\hline
\end{tabular}

SD, standard deviation.

a Significantly different from Erkodur at the same time point by Bonferroni's test.

${ }^{\text {b }}$ Significantly different from Masel at the same time point by Bonferroni's test. 


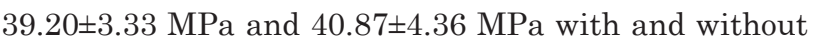
chamber loading, respectively. No obvious difference (independent $t$ test, $p=0.209$ ) was found, indicating that the potential influence of physical fixing on the stress behavior is rather weak or negligible. This result is consistent with the previous assumption that the deformation and, therefore, the stress originate from the middle narrow part of the dumbbell-shaped specimen $^{16,17)}$, and also indicates that the differences in stress relaxation observed here should result from the testing environments (i.e., temperature and moisture) or/and material types.
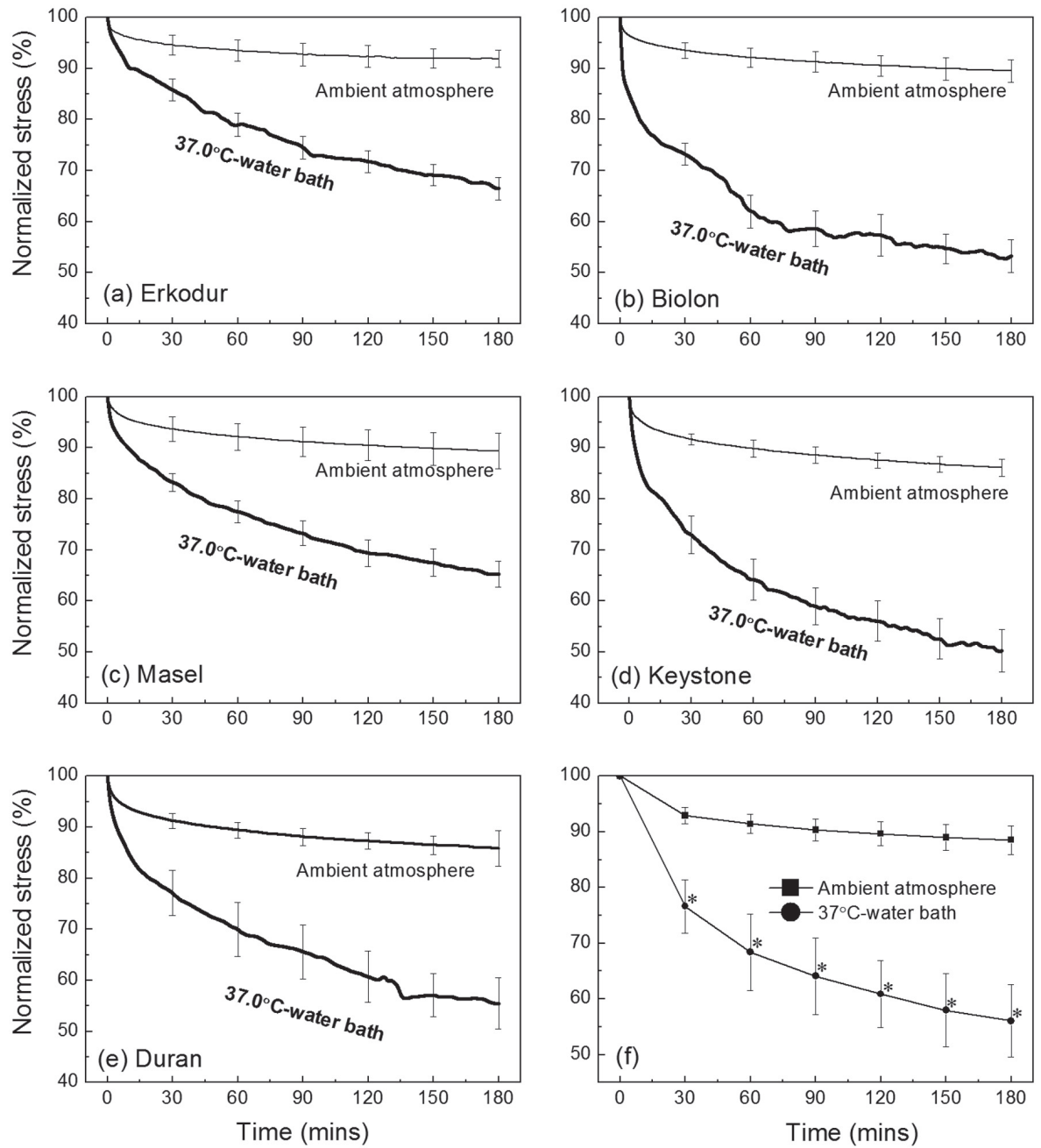

Fig. 2 Stress relaxation curves of the five tested materials (a-e) and average residual stress (\%) at selected time points (f) under both environments.

For each material, the stress relaxation curves were averaged from three individual specimens; and only the standard deviation values at 30,60, 90, 120, 150, and 180 min were shown for comparison with the selected average residual stress values of different materials. Compared with those within ambient atmospheric environment, the stress relaxation curves obtained within $37^{\circ} \mathrm{C}$-water bath are a little noisy, possibly due to mechanic disturbance of water flow.

*Significantly different from the average residual stress at the same time point in the ambient atmospheric environment. 
point is significantly lower than the previous one $(p<0.05)$. However, stress-strain behavior in the $37.0^{\circ} \mathrm{C}$ water bath was significantly different from that in the ambient atmospheric environment $(p<0.05$, material type not included as a variable). Specifically, at each selected time point, residual stress in the former environment was significantly lower than the latter $(p<0.05$; material type not included as a variable). These results confirm that a hygrothermal aging environment can accelerate stress relaxation of thermoplastic materials $^{18-21)}$

The stress relaxation behavior also differs among different materials within the same testing environment $(p<0.05)$. More specifically, within the ambient atmospheric environment, Erkodur shows the slowest relaxing rate. Its residual stress is significantly higher than Duran from 90-180 min, Keystone from 120-180 min, and Masel at $180 \mathrm{~min}(p<0.05)$. In contrast, in the $37.0^{\circ} \mathrm{C}$ water bath, Erkodur and Masel had much slower stress relaxation than the other three materials, i.e., the residual stress of Erkodur and Masel is higher than the other materials at all selected time points (except at zero $\mathrm{min}$ ).

It should be noted that there was no obvious plateau of stress relaxation for all materials, especially for those under the simulated oral environment. A reasonable interpretation might be short duration or/ and relatively small deformation (5\% strain) used in the present study.

\section{DISCUSSION AND CONCLUSIONS}

The mechanical properties of thermoplastic materials are known to strongly depend on the material types and environmental conditions in which they are used $^{14,15)}$. Understanding the mechanical behaviors of orthodontic thermoplastics within an oral environment is an essential requisite for screening materials for appliances. Such a study is also crucial to better understand the orthodontic mechanism and process of Invisalign. In the past decade, various approaches or specific instruments have been developed to study the mechanical properties (including instantaneous forces and moments) of different thermoplastic materials in clinically-relevant situations ${ }^{22-24)}$. This study developed a practical and economical temperature-controlled water bath system, which holds the specimen under a controllable environment. Through a combination of commercial testing equipment (ELF 3100), dynamic stress relaxation of thermoplastic materials can be measured within a simulated oral environment (e.g., water bath at $37.0^{\circ} \mathrm{C}$ as in this study). Furthermore, if needed this system can also be used to characterize the mechanical properties of thermoplastic materials at various temperatures and in fluid environments by regulating the temperature of the water bath or/and changing the circulated liquid (e.g., artificial saliva).

The present study clearly shows that the hygrothermal aging environment can significantly accelerate the stress relaxation of orthodontic thermoplastic material, but the mechanism is still unclear. Numerous studies indicate water absorption may contribute to the stress relaxation of thermoplastic materials. Bao et $a l .{ }^{18)}$ found that in bismaleimide resin, absorbed water accelerated the relaxation of the matrix through a process called plasticization. Boubakri et $a .^{19,20)}$ confirmed this irreversible phenomenon in thermoplastic polyurethane and pointed out that the nature of plasticization was increased mobility of chains' macromolecular segments. The authors believed that water absorption may induce a breakup of the intrachain and/or interchain hydrogen bonds and modify the free volume of the polymers. Hollande et al. ${ }^{21)}$ also observed that absorbed water may wash out soluble substances in polymers, which accelerates the degradation process. On the other hand, thermal aging was found to increase mechanical properties like Young's modulus and the tensile stress of polymers. However, in a hygrothermal aging environment, temperature promoted water diffusion in polymers, therefore accelerating degradation ${ }^{19)}$. In our study, significant differences between materials arises since $90 \mathrm{~min}$ in the atmospheric environment, whereas it is observed from the start in the $37^{\circ} \mathrm{C}$-water-bath environment. This confirms that the process of water absorption and temperature discriminately taxes different materials, probably owing to their different susceptibilities to water and/or the amount of water intake.

The ideal orthodontic force should be a 'light, continuous force', as stated by Proffit ${ }^{10)}$. For tipping movement, the ideal force is suggested as 35-60 g. This study indicates that both material type and the environment where they are used should be considered in clinical situations. For instance, materials delivered only $42.29-66.56 \%$ of their initial forces after immersion in the $37^{\circ} \mathrm{C}$ water bath for $3 \mathrm{~h}$. Therefore, the 'ideal' initial force might be unable to activate the biochemical process in the periodontal ligament (PDL) over time. Moreover, compared with the $37^{\circ} \mathrm{C}$ water bath used in this study, the in vivo oral environment is much more complicated, not only in chemistry but also in periodic removal and reinsertion of aligners. Therefore, further experiments dedicated to studying the mechanical properties of orthodontic thermoplastics within more temperature, duration, and chemical environments, i.e., periodically altered temperature, weekly or monthly duration, artificial saliva, and various thickness of specimen, are extremely needed.

Based on this study performed in a simulated oral environment, Masel and Erkodur are relatively less affected among the five materials, showing a slower stress relaxation rate with time in the hygrothermal aging environment than the other three materials. A further comparative study on the chemical composition and molecular structure of these five materials is needed in the near future to understand the relationship between the mechanical properties and the chemicophysical features. Nevertheless, this study set up a temperature-controlled water bath system which can be used to study the mechanical properties 
of orthodontic thermoplastic materials within temperature, liquid, and time-controlled environments. From a clinical perspective, Masel and Erkodur might be good candidates for delivering more stable forces to target teeth.

\section{ACKNOWLEDGMENTS}

This work was supported by the National Natural Science Foundation of China (NSFC grant No. 81271184) and the Beijing Municipal Science and Technology Commission, China (Grant No. Z121107001012008). We thank Mr. Hui Wang, Mr. Baoping Wu, Mr. Weixi $\mathrm{Ke}$ and Ms. Xiuqing Qian for their assistance with experiments. We are grateful to the editor and two anonymous reviewers for their constructive comments that significantly improved the original manuscript.

\section{REFERENCES}

1) Sheridan JJ, Ledoux W, McMinn R. Essix technology for the fabrication of temporary anterior bridges. J Clin Orthod 1994; 28: $482-486$.

2) Sheridan JJ, Armbruster P. Bleaching teeth during supervised retention. J Clin Orthod 1999; 33: 339-344.

3) Oh WS, Wang C. Use of thermoplastic vacuum-formed matrix for emergency management of crown-root fracture. J Prosthet Dent 2007; 98: 335-336.

4) Lloyd T, Nightingale C, Edler R. The use of vacuumformed splints for temporary intermaxillary fixation in the management of unilateral condylar fractures. $\mathrm{Br} \mathrm{J}$ Oral Maxillofac Surg 2001; 39: 301-303.

5) Joffe L. Invisalign: early experiences. J Orthod 2003; 30: 348352.

6) Rosvall MD, Field HW, Ziuchkovski J, Rosenstiel SF, Johnston WM. Attractiveness, acceptability, and value of orthodontic appliances. Am J Orthod Dentofacial Orthop 2009; 135: 276 288.

7) Jeremiah HG, Bister D, Newton JT. Social perceptions of adults wearing orthodontic appliances: a cross-sectional study. Eur J Orthod 2010; 33: 476-482.

8) Kravitz ND, Kusnoto B, BeGole E, Obrez A, Agran B. How well does Invisalign work? A prospective clinical study evaluating the efficacy of tooth movement with Invisalign. Am J Orthod Dentofacial Orthop 2009; 135: 27-35.

9) Kuncio D, Maganzini A, Shelton C, Freeman K. Invisalign and traditional orthodontic treatment postretention outcomes compared using the American Board of Orthodontics objective grading system. Angle Orthod 2007; 77: 864-869.
10) Proffit WR, Fields HW, Sarver DM. Contemporary orthodontics. 4th ed. St. Louis: Mosby; 2007.

11) Tricca R, Li C. Properties of aligner material Ex30. In: Tuncay OC. The invisalign system. Philadelphia: Quintessence; 2006. p. $177-186$.

12) Zhang N, Bai Y, Ding X, Zhang Y. Preparation and characterization of thermoplastic materials for invisible orthodontics. Dent Mater J 2011; 30: 954-959.

13) Goldberg AJ, Libler SA, Burstone CJ. Viscoelastic properties of an aesthetic translucent orthodontic wire. Eur J Orthod 2010; 33: 673-678.

14) Ryokawa H, Miyazaki Y, Fujishima A, Miyazaki T, Maki K. The mechanical properties of dental thermoplastic materials in a simulated intraoral environment. J Orthodontic Waves 2006; 65: 64-72.

15) Gould TE, Piland SG, Shin J, Hoyle CE, Nazarenko S. Characterization of mouthguard materials: Physical and mechanical properties of commercialized products. Dent Mater 2009; 25: 771-780.

16) ISO 527-3. Plastics - Determination of tensile propertiesPart 3: Test conditions for films and sheets. ISO; 1995.

17) ISO 527-1. Plastics - Determination of tensile propertiesPart 1: General principles. ISO; 1993.

18) Bao LR, Yee AF, Lee CYC. Moisture absorption and hygrothermal aging in a bismaleimide resin. Polymer 2001; 42: 7327-7333.

19) Boubakri A, Haddar N, Elleuch K, Bienvenu Y. Impact of aging conditions on mechanical properties of thermoplastic polyurethane. Mater Design 2010; 31: 4194-4201.

20) Boubakri A, Elleuch K, Guermazi N, Ayedi HF. Investigations on hygrothermal aging of thermoplastic polyurethane material. Mater Design 2009; 30: 3958-3965.

21) Hollande S, Laurent JL. Weight loss during different weathering tests of industrial thermoplastic elastomer polyurethane-coated fabrics. Polym Degrad Stabil 1998; 62: 501-505.

22) Hahn W, Dathe H, Fialka-Fricke J, Fricke-Zech S, Zapf A, Kubein-Meesenburg D, Sadat-Khonsari R. Influence of thermoplastic appliance thickness on the magnitude of force delivered to a maxillary central incisor during tipping. Am J Orthod Dentofacial Orthop 2009; 136: 12.e1-e17.

23) Hahn W, Engelke B, Jung K, Dathe H, Fialka-Fricke J, Kubein-Meesenburg D, Sadat-Khonsari R. Initial forces and moments delivered by removable thermoplastic appliances during rotation of an upper central incisor. Angle Orthod 2010; 80: 239-246.

24) Barbagallo LJ, Shen G, Jones AS, Swain MV, Petocz P, Darendeliler MA. A novel pressure film approach for determining the force imparted by clear removable thermoplastic appliances. Ann Biomed Eng 2008; 36: 335341. 